\title{
Grey literature
}

\section{Advocating for diverse voices, increased use, improved access, and preservation}

G rey literature $(\mathrm{GL})$, or works that are more ephemeral in nature and not produced by traditional publishers, plays an important role in research and teaching. Some disciplines, such as economics and forestry, rely on and value GL for how it allows rapid dissemination of information. Additionally, as systematic reviews become increasingly popular in a wider variety of disciplines, the focus on GL has intensified due to guidelines calling for its inclusion. These factors led the authors to further explore the role of GL across disciplines of our institution. We examined the current levels of GL in databases and institutional repositories, and surveyed and interviewed faculty on their relationship with GL. This research found a lack of diverse voices in GL holdings and issues in preservation and access. Libraries are well situated to address these issues and in this article we argue that they should: increase the collection of diverse voices in GL, preserve digital born materials, and provide access to GL. Finally, we offer several ways that libraries can accomplish this goal.

\section{Authors' research into GL}

Our first study examined the amounts of GL found in more than 170 commercial databases across many disciplines to which our institution subscribes, and the amount of GL found in the institutional repositories (IR) of Association of Research Libraries (ARL) member libraries. ${ }^{1}$ We found more GL in the commercial databases than expected, allowing for greater discovery than anticipated. With IRs, while GL was present, it was not systematically collected, with the exception of theses and dissertations. Our next study examined the use, creation, and citation of GL by faculty across the disciplines of our institution. ${ }^{2}$ We found that faculty create and use GL regardless of discipline, and they find it most often through Google searches or professional contacts. Additionally, interviews revealed that many faculty produce GL with lay audiences in mind, such as practitioners in the field. ${ }^{3}$ Several faculty also mentioned using it in their undergraduate instruction for its timeliness and accessible language.

While this research demonstrated GL use and creation across disciplines, it also highlighted several issues. The following sections provide ways librarians can address these issues at their own institutions.

\section{Collecting diverse voices in library collections with grey literature}

After the murder of George Floyd, many li-

\footnotetext{
Wanda Marsolek is engineering liaison and data curation librarian, email:mars0215@umn.edu, Shannon L. Farrell is natural resources librarian, email: sfarrell@ umn.edu, Julia A. Kelly is science librarian, email: jkelly@umn.edu, and Kristen Cooper is plant sciences librarian, email: coope377@umn.edu, at the University of Minnesota
}

(c) 2021 Wanda Marsolek, Shannon L. Farrell, Julia A. Kelly, and Kristen Cooper 
braries, nonprofits, and corporations made statements and promises to become more antiracist in their practices, such as amplifying traditionally silenced voices. Libraries have the opportunity to diversify the perspectives and opinions presented in library collections by collecting GL that exists outside of traditional publishing avenues.

One way to incorporate more GL is via collection development policies. For example, the University of Minnesota's Natural Resources Library (NRL) collection development policy specifically discusses its inclusion. NRL actively collects material from a wide variety of non-governmental organizations and nonprofits, including foreign language reports from developing nations. In many cases, finding and acquiring these materials is not straightforward. NRL staff have generated a list of well-respected organizations and content creators who distribute works that are important but not traditionally published or available from our ebook and book vendor. Staff purchase materials, if possible. For materials that cannot be purchased, staff contact the organizations for permission to print and add to the collection.

While interviewing faculty members about their creation and use of GL, we found that many faculty see GL as essential to highlight timely viewpoints not captured elsewhere.

For example, in some South American or Caribbean countries, new findings are often presented in reports written in Spanish via government agencies or nonprofit organizations. Without GL publications, these findings are unavailable. One interview participant discussed how GL's inclusion impacted the work of the Intergovernmental Panel on Climate Change (IPCC): "The IPCC, which is seen as probably the most credible United Nations-sanctioned report on climate, have very extensive guidelines about GL. It became politicized in the sense that there was a strong sense by a lot of participants from developing countries that their research was only in GL and it became this political issue where one of the developing country authors really wanted more GL [included] so that their country's work could be represented." ${ }^{4}$
Libraries can take small steps, such as incorporating GL into their collection statements for disciplines that rely on GL. GL published by indigenous, local, national, and international organizations whose work focuses on developing policies or sharing timely information can diversify library collections and make hard-tofind information accessible to our communities.

\section{Preserving born digital grey literature in library collections}

As scholarly communication and open access to literature becomes more important, born digital GL becomes more prevalent. How do libraries collect born digital GL? PDFs can be saved, but how can we archive them and allow others to access them? Where do we store them: servers, the cloud, repositories? Can we add them to our online catalog? Do we print them and have them cataloged?

One of the many benefits of printing GL is having it on the shelf surrounded by like topics, allowing users to browse and locate it via serendipity. More importantly, printing and cataloging allows GL to gain permanence. It is no longer subject to link rot or website instability. Some may assume that the Internet Archive protects GL documents on the open web, but it does not capture the whole Internet. Even if the top levels of a site are captured, there may not be access to all layers and links on the preserved site. Printing out and cataloging takes preservation a step further by securing access to these valuable documents beyond the capabilities of the Internet Archive.

NRL's forestry collection includes a substantial amount of GL. Many institutions depend on copy cataloging. When new documents are not collected by many libraries, copy cataloging is not an option, and original cataloging is necessary. To save time and resources, NRL subject area support staff devised a quick catalog method using OCLC's searchFAST and assignFAST through a Google Form in collaboration with our cataloging department. This includes very simple original cataloging-title, author, year, and three headings/keywords. This process is time consuming and laborious, but also time necessary to make these resources available to 
researchers and the community which, as a land grant institution, we have a responsibility to do.

Printing and cataloging GL takes time and effort, but it does help preserve GL that is born digital in a stable way. Cataloging aids in discovery and access at the holding library, as well as for others around the world to locate via OCLC.

\section{Providing access to grey literature in library collections}

Few organizations producing GL or libraries collecting GL have systematically worked to make these items findable or safe from disappearing. GL is often produced by small organizations that use their websites as their distribution mechanism, and they do not see themselves in the preservation business. As with other more ephemeral forms of scholarship, GL is always at risk of disappearing. ${ }^{5}$

The discoverability and archiving of GL does not easily fit into the current library landscape in which large publishers produce materials that are purchased or leased and cataloged by libraries and indexed in widely available electronic indices. While preservation methods for these print and electronic materials are not perfect, both publishers and libraries are making an effort. Examples include preservation archives, such as Portico or shared consortial agreements. GL is seldom added to academic library collections in a comprehensive way, although exceptions exist. One situation in which academic libraries actively collect GL are for their "collections of distinction," which are collections that are unique to the institution, and are deep and rich in a variety of resources on a topic. They are often built to match a strong academic program at the institution.

In the early days of the web when search engines were in their infancy, librarians embarked on projects such as $\mathrm{AgNIC}^{6}$ and HealthWeb, ${ }^{7}$ which were curated and organized lists of resources on a defined topic, such as blueberries or hematology, and they often included GL. As search engines became much more sophisticated, these projects were discontinued.

Even a large entity like the U.S. federal government, which produces large numbers of reports and other documents, has not resolved issues around findability and preservation. This is a problem for systematic reviews, which require documentation of search strategies such that someone else can repeat them. Different government agencies use different platforms for search and retrieval, making it difficult to determine how to effectively identify relevant documents across platforms. Further, these search mechanisms are rudimentary, and features such as exporting citations and/or documents may not exist. These works are rich sources of research data that are timely, but have often not been published in other outlets. Not all government documents are covered under these search systems, and there is still the common problem of documents disappearing and not being preserved.

And, finally, to circle back to our original concern of the importance of diverse voices, these databases and sources are primarily include U.S. federal government documents, rarely state and regional documents, and are lacking indigenous or other nations outside of the United States.

\section{Conclusion}

Librarians have done and continue to do the important work of collecting GL, preserving it, and providing access to it. For those who are collecting GL, in solidarity we thank you and ask you to please continue the work, and we welcome commentary about your successes and shortfalls. We encourage those who are not collecting GL to begin talking with your colleagues about how collecting it could be an opportunity for your organizations and the steps you could take to move forward. We provide three areas with action items where librarians can advocate for the field to be better at collecting, preserving, and providing access to GL.

\section{Collect diverse voices in library collections with grey literature}

- Incorporate GL into collection development statements for subject areas that use and value GL.

- Be deliberate in establishing more diverse government document collections by actively 
collecting indigenous and international perspectives.

- Encourage GL producers in your communities to collaborate with existing subject repositories, like AgEcon Search and Digital Library of the Commons, that currently include various types of GL.

\section{Preserve born digital grey literature in li- brary collections}

- Develop a workflow to catalog born digital GL.

- Invite library publishing platforms to support the promotion and inclusion of conference proceedings and other types of GL. An example is the Safe Pork conferences published by Iowa State University. ${ }^{8}$

\section{Provide access to grey literature in library collections}

- Advocate for more comprehensive inclusion of GL in indexes and IRs. A recent study ${ }^{9}$ noted that GL is included in a number of indexes regularly used by academic researchers but not always in a thorough or comprehensive manner.

- Support campus GL producers to deposit GL in your IR, using the available existing infrastructure.

- Propose including materials from professional organizations and other nonprofits in your IR. The current scope of many IRs requires that at least one author of each work be affiliated with the institution, but there are examples of institutions working outside of these boundaries. Examples include the USAIN conference papers and posters in eCommons at Cornell University $^{10}$ and People of Color in Predominantly White Institutions conference papers in Digital Commons@University of Nebraska. ${ }^{11}$

\section{Notes}

1. Wanda R. Marsolek, Kristen Cooper, Shannon L. Farrell, and Julia A. Kelly, "The types, frequencies, and findability of disciplinary grey literature within prominent subject databases and academic institutional repositories," Journal of Librarianship and Scholarly Communication 6, no. 1 (2018).
2. Kristen Cooper, Wanda Marsolek, Amy Riegelman, Shannon Farrell, and Julie Kelly, "Grey Literature: Use, Creation, and Citation Habits of Faculty Researchers across Disciplines," Journal of Librarianship and Scholarly Communication 7, no. 1 (2019).

3. Wanda Marsolek, Kristen Cooper, Amy Riegelman, Shannon L. Farrell, and Julia A. Kelly, "Faculty Perceptions of Grey Literature: A Qualitative Analysis of Faculty Interviews," Grey Journal (TGJ) 16, no. 3 (2020).

4. Climate Change 2014: Synthesis Report. Contribution of Working Groups I, II and III to the Fifth Assessment Report of the Intergovernmental Panel on Climate Change [Core Writing Team, R. K. Pachauri and L. A. Meyer (eds.)], IPCC, Geneva, Switzerland, (2014).

5. Mikael Laakso, Lisa Matthias, and Najko Jahn, "Open is not forever: A study of vanished open access journals," arXiv preprint arXiv:2008.11933 (2020).

6. Heather K. Moberly and Melanie A. Gardner, "Creating Distributed Information Access: The Agriculture Network Information Center (AgNIC)," Technical Services Quarterly 17, no. 3 (2000): 33-46.

7. Patricia M. Redman, Anthony R. Aguirre, Doreen R. Bradley, and Darin C. Savage, "HealthWeb: A collaborative interinstitutional Internet project," Library Hi Tech (1998).

8. International Conference on the Epidemiology and Control of Biological, Chemical and Physical Hazards in Pigs and Pork | Conferences and Symposia | Iowa State University, accessed October 18, 2020, https://lib.dr.iastate.edu/safepork.

9. Wanda R. Marsolek, Kristen Cooper, Shannon L. Farrell, and Julia A. Kelly, "The types, frequencies, and findability of disciplinary grey literature within prominent subject databases and academic institutional repositories," Journal of Librarianship and Scholarly Communication 6, no. 1 (2018).

10. United States Agricultural Information Network (USAIN) | Cornell University, accessed October 18, 2020, https://ecommons.cornell.edu /handle/1813/39483.

11. People of Color in Predominantly White Institutions | University of Nebraska, accessed October 18, 2020, https://digitalcommons. unl.edu/pocpwi. $\approx$ 